Running Head: PERCEPTIONS SOCIAL RESOURCE INEQUALITY

\author{
Children's Perceptions of Social Resource Inequality
}

\author{
Laura Elenbaas \& Melanie Killen \\ University of Maryland
}

submitted to the Journal of Applied Developmental Psychology October 15, 2015

revised and resubmitted June 21, 2016

revised and resubmitted October 3, 2016 


\begin{abstract}
Children's perceptions of social resource inequalities were investigated by measuring spontaneous explanations for race-based disparities in access to societal resources. Fifth graders $(N=139, M=11.14$ years, $S D=.61$ years $)$ viewed animated vignettes depicting hypothetical resource inequalities between institutions serving children of African-American and EuropeanAmerican background. Children frequently explained disparities in terms of institutions' differing financial resources, revealing awareness that economic inequalities often underlie groups' differential access to societal resources. Further, children attributed inequalities to preferential treatment more often when they witnessed African-Americans at a disadvantage than when they witnessed European-Americans at a disadvantage, demonstrating awareness that racial minority groups are more likely to experience restricted access to resources. Finally, children who reasoned about preferential treatment judged inequality, and actions that perpetuated inequality, more negatively than children who attributed inequalities to institutions' differing needs, revealing a link between awareness of discrimination and rejection of social inequalities.
\end{abstract}

Key words: Social cognition; reasoning; resource inequality; bias 


\section{Children's Perceptions of Social Resource Inequality}

Throughout development, children are aware of resource inequality. Research on children's moral judgments, for example, has demonstrated children's negative evaluations of unequal resource distribution between peers (Killen \& Smetana, 2015). Other research has likewise revealed that children are aware of inequality on a broader level. By the end of elementary school, for example, children identify whether individuals are rich or poor based on their material possessions (Horwitz, Shutts, \& Olson, 2014; Mistry, Brown, White, Chow, \& Gillen-O'Neel, 2015). While research on children's moral judgments about resource distribution has revealed reasoning about fairness, justice, and other's welfare (Killen, Elenbaas, Rizzo, \& Rutland, 2016), research on children's reasoning about the causes of wealth and poverty has often revealed assumptions linking economic disparities with differences in effort and intelligence (Chafel \& Neitzel, 2005; Flanagan et al., 2014). The current study investigated children's reasoning about social resource inequality, which reflects a new area at the intersection of fairness judgments and knowledge about intergroup relations.

\section{Theoretical Framework: Social Reasoning Developmental Model}

In order to frame the current study, we drew on an integrative theoretical model called the social reasoning developmental (SRD) model, which emphasizes the importance of both moral concerns about fairness as well as group affiliations and expectations throughout development (Killen, Elenbaas, \& Rutland, 2015; Rutland, Killen, \& Abrams, 2010). This theoretical model draws on extensive work on moral development from the perspective of social domain theory (Smetana, Jambon, \& Ball, 2014; Turiel, 2006) as well as developmental social identity theories concerning the development of intergroup attitudes (Abrams \& Rutland, 2008; Nesdale, 2004; Verkuyten, 2007). 
Considerable research on children's intergroup attitudes has focused on the negative aspects of group membership and children's treatment of others (e.g., in-group biases, prejudice). The SRD model likewise posits that, in many social contexts, children's stereotypes and biases can lead them to treat others unfairly. For example, children exclude, tease, and shun peers based on stereotypes about group memberships like race or gender (Killen et al., 2015). However, the SRD model proposes that knowledge about intergroup relations can also contribute to, rather than impede, the promotion of fairness in childhood.

Social knowledge about intergroup relations can include recognition of when relations between groups have been unfair. In fact, with age, children gain increasing awareness of how norms about intergroup relations are not always acceptable from a moral viewpoint. For instance, relative to young children, early adolescents are better able to distinguish their expectations for how members of groups will interact from their judgments about how individuals should relate to one another (e.g., Hitti \& Killen, 2015; Mulvey, Hitti, Rutland, Abrams, \& Killen, 2014; Mulvey \& Killen, 2015). Research drawing on the SRD model has demonstrated how this developing knowledge about how groups work can contribute to children's decisions to challenge unfair group practices, including the exclusion of peers from social "out-groups" (Killen \& Rutland, 2011).

In the context of the current study, the SRD model predicts that when children recognize that intergroup relations have been unfair in the past, they can use that knowledge to advocate for fair relations between groups in the present. The SRD model generated novel hypotheses regarding relations between children's explanations for observed resource inequalities between groups and their judgments about the wrongfulness of resource inequalities and actions taken to 
perpetuate them. The following three sections outline the aims of the study and introduce related research in this area before turning to our specific hypotheses.

\section{Children's Explanations for Group-Based Resource Inequality}

The first aim of the current study was to investigate children's self-generated explanations for observed inequalities of resources between racial groups. By 10-11 years of age, children are aware that different social groups, including racial groups, often differ in economic status (Bigler, Averhart, \& Liben, 2003; Elenbaas \& Killen, 2016a; Newheiser \& Olson, 2012; Shutts, Brey, Dornbusch, Slywotzky, \& Olson, 2016). What is not yet known is whether children are likewise aware that disparities in group economic status often underlie observed racial inequalities in access to societal resources. Economic disparities are a primary form of inequality. That is, while inequalities in access to societal resources like quality education and health care often map on to other group categories (including race), economic inequalities are the form that underlies inequality in most other domains (Saegert et al., 2007).

Notably, the existing literature suggests that knowledge about the economic underpinnings of resource inequality between groups is slow to develop. For example, with few exceptions (Chafel \& Neitzel, 2005; Hussak \& Cimpian, 2015), studies have shown that children do not spontaneously consider how social factors (e.g., insufficient educational or job opportunities) contribute to differences in individuals' economic status until 12-18 years of age (Arsenio, Preziosi, Silberstein, \& Hamburger, 2013; Flanagan et al., 2014; Goodman et al., 2000; Mistry, Brown, Chow, \& Collins, 2012). Younger children have also been shown to perceive certain group-based resource inequalities to be deserved, and to assume that the way things are is the way that they are supposed to be (McGillicuddy-De Lisi, Daly, \& Neal, 2006; Olson, Dweck, Spelke, \& Banaji, 2011). Likewise there are many instances in which adults rationalize or 
legitimize existing inequalities between groups, fulfilling a psychological need to understand the status quo as good, fair, natural, desirable, and inevitable (Jost, Banaji, \& Nosek, 2004; Jost \& Banaji, 1994).

Whether or not children are aware of the links between economic disparities and groups' unequal access to societal resources has important implications for their social relations with, and attitudes towards, advantaged and disadvantaged peers. By the end of the elementary years, for example, children endorse stereotypes linking economic success with personal merits (e.g., hard work, intelligence) and economic disadvantage with personal failings (e.g., laziness) (Shutts et al., 2016; Sigelman, 2012; Woods, Kurtz-Costes, \& Rowley, 2005), and further exclude stigmatized peers based on these stereotypes (Abrams \& Killen, 2014; Bucchianeri, Eisenberg, \& Neumark-Sztainer, 2013). Thus, understanding children's assumptions about the causes of social resource inequality provides a window on the origins of stereotypes that reinforce a damaging cycle of inequality (Abrams \& Killen, 2014; Brown \& Bigler, 2005).

There is reason to believe, however, that children may recognize some of the economic factors that contribute to group disparities in access to societal resources prior to adolescence. First, unlike individual differences in economic status, race-related differences in access to societal resources are group-level concerns, bringing group-level factors like associations of race and wealth to the forefront. By the end of the elementary years, children are aware that different social groups, including racial groups, often differ in economic status (Bigler et al., 2003; Elenbaas \& Killen, 2016a; Newheiser \& Olson, 2012; Shutts et al., 2016). They may, accordingly, be able to recognize some of the economic factors underlying a clear-cut racial disparity in access to societal resources. Thus, in the current study, we presented 10-11 year-old 
participants with several examples of unequal allocation of educational and health care resources based on race, and measured their self-generated explanations for the inequalities.

\section{Explanations for Inequality Based on Group Race}

Building on this point, in the United States, children from certain racial groups are, on average, more likely to experience restricted access to resources than are children from other racial groups. For example, African-American children are, on average, more likely to attend under-resourced schools than are European-American children (Duncan \& Murnane, 2011). The second goal of the current study was to determine whether children are aware of discrimination as a cause of resource inequality (in addition to economic disparities between groups, as outlined above), and whether the race of the group that is observed to be receiving fewer resources impacts children's likelihood of attributing a resource inequality to discrimination. That is, while the first aim of the study asked whether children recognize that economic factors contribute to groups' access to resources, the second aim asked whether children were more likely to perceive resource inequality as discrimination when African-American children were disadvantaged than when European-American children were disadvantaged.

Related research on children's awareness of others' biases has revealed that, by 10-13 years of age, children are aware that, in certain contexts, members of racial/ethnic minority groups are more likely to be the targets of discrimination than European-Americans (Brown, Mistry, \& Bigler, 2007; J. M. Hughes, 2011; McKown \& Strambler, 2009). This work has largely focused on specific instances of bias, examining, for example, children's knowledge of historical events pertaining to race and differential treatment. Children may also be more likely to detect discrimination when a racial minority group receives fewer resources than a racial majority group, though this possibility has not yet been tested empirically. Thus, we presented 
participants in the current study with two scenarios: one in which institutions serving AfricanAmericans were receiving fewer resources, and one in which institutions serving EuropeanAmericans were receiving fewer resources. Then, we tested for differences in children's explanations for resource inequality based on the race of the disadvantaged group.

Whether or not children perceive discrimination to be more likely when certain groups are targeted for restricted access to resources has important implications for how they may respond to that inequality. There is little evidence that adopting a "color-blind" approach sufficiently prepares children to combat issues of inequality in their own lives or in society (Elenbaas \& Killen, 2016b; D. Hughes, 2003; Levy, West, \& Ramirez, 2005; Pahlke, Bigler, \& Suizzo, 2012). Rather, in order to reject unfair patterns of distribution, children must first be able to recognize them as such. Thus, the third and final aim of the current study was to test for relations between children's self-generated explanations for the inequalities that they observed and their judgments about the wrongfulness of these disparities and actions taken to perpetuate them.

\section{Relations between Explanations for Inequality and Judgments about Inequality}

Thus, the current study measured children's explanations for the causes of resource inequalities between groups, and used differences in these explanations to predict children's moral judgments about the inequalities that they observed. While few studies have taken this approach, information about how children's differing perceptions of inequality contribute to their judgments about how disparities should be addressed provides important information for the development of effective educational programs to expand opportunities for disadvantaged groups. One study, for example, found that high schoolers (14-17 year-olds) who knew more about historical racism and attributed disparities in society to racism were more supportive of a 
program providing assistance with college applications to African-American and Latino students (a historically under-represented college population) (J. M. Hughes \& Bigler, 2011). Likewise, another study found that a workshop designed help participants identify racial biases in the workplace and develop strategies to counteract them increased 10-13 year-old African-American children's expectations for the status of the job that they would one day have (J. M. Hughes, 2011). In short, awareness of the unfair and discriminatory nature of group-based disparities helps adolescents challenge status quo inequalities.

The same relations between perceptions of inequality and judgments of inequality may be present in older elementary schoolers. We tested this question directly by determining the extent to which children's explanations for the disparities that they observed predicted their judgments about the wrongfulness of inequality and actions taken to perpetuate it. By presenting straightforward disparities of familiar resources between peers, we aimed to examine earlier origins of the relation between children's perceptions of inequality and their judgments about inequality.

We examined children's explanations for and judgments of inequalities of school supplies and medical supplies because, while the majority of research on children's judgments about resource inequality has focused on inequalities of small, desirable resources like candy and toys, related work indicates that, by age 9-11 years, children support their own and others' rights to societal resources including quality education and medical care (Peterson-Badali, Morine, Ruck, \& Slonim, 2004), and increasingly reject biased policies regarding the distribution of such resources (Helwig \& Jasiobedzka, 2001; Killen, Lee-Kim, McGlothlin, \& Stangor, 2002). This suggests that racial inequalities of educational and health care supplies may be especially salient for children by 10-11 years of age. Children who attribute such inequalities to discrimination, for 
example, may be especially likely to judge them negatively, and reject further biased allocation behavior that perpetuates inequality. We presented inequalities of both educational and health care resources in the current study in order to gain a more generalized understanding of children's perceptions of social inequalities than would be provided by one context alone.

\section{Hypotheses for the Current Study}

Thus, the current study: 1) measured 10-11 year-olds' spontaneous self-generated explanations for inequalities of societal resources (educational and health care supplies) between racial groups, 2) tested whether children's explanations for inequality varied based on the race of the group receiving fewer resources, and 3) examined the extent to which children's selfgenerated explanations for the disparities predicted their judgments about the wrongfulness of inequality and discriminatory actions taken to perpetuate it.

The age of 10-11 years (fifth grade) was chosen because, as outlined above, children's recognition of racial disparities in economic status has been demonstrated to emerge around this age, as has recognition of differential treatment based on race as potentially discriminatory. What is not yet known is whether children recognize some of the economic factors underlying resource inequality are more likely to perceive discrimination when African-American children are disadvantaged, or make different judgments about inequalities based on their attributions for the cause of observed disparities.

One possibility is that children may interpret racial inequalities is access to resources like quality education and health care similarly to how they interpret individual inequalities in economic status (i.e., assuming that groups with more resources are more meritorious whereas groups with fewer resources are less deserving). In this case, they may endorse inequalities of these resources as legitimate. Another possibility is that children may recognize that group 
disparities in access to these societal resources are often linked to societal factors like racial discrimination and economic disparities between groups. In this case, they may reject inequalities of these resources as unfair and morally wrong.

Additionally, most studies of children's evaluations of resource inequality have been conducted with predominantly European-American samples. In the current study, AfricanAmerican, European-American, Latino, and Asian-American children were included as participants. While there is some evidence that older African-American and Latino children are more perceptive of discrimination than their European-American and Asian-American peers (Bigler, Arthur, Hughes, \& Patterson, 2008; Brown, Alabi, Huynh, \& Masten, 2011; McKown \& Weinstein, 2003; McKown, 2004), other studies do not find racial/ethnic differences in children's ability to detect discrimination (Brown, 2006; McKown \& Strambler, 2009). Thus, this study included a racially/ethnically diverse sample in order to determine whether or not children's own racial/ethnic background would contribute to their reasoning about resource inequalities between groups.

Based on previous research, we expected that 10-11 year-olds' spontaneous selfgenerated explanations for the inequality would include references to preferential treatment of one social group over the other (Killen et al., 2016, 2002), to money or the economic resources of the institutions (Chafel \& Neitzel, 2005; Mistry et al., 2012), and to the relative needs of the populations served (Schmidt, Svetlova, Johe, \& Tomasello, 2016; Sigelman \& Waitzman, 1991). We hypothesized that children would be more likely to explain resource inequality in terms of preferential treatment when institutions serving African-Americans were observed to be receiving fewer resources than institutions serving European-Americans (versus when EuropeanAmericans were observed to be at a disadvantage), based on related research indicating that, by 
middle childhood, children have an emerging recognition that discrimination is most often directed toward racial/ethnic minority, rather than majority, groups (Bigler et al., 2008; Brown et al., 2007; J. M. Hughes, 2011).

We predicted that, in comparison to children who attributed the inequality to differing needs (i.e., one group having a greater need for resources than the other), children who attributed it to preferential treatment or to differences in financial/economic resources between institutions would judge the inequality more negatively and would evaluate actions taken to perpetuate it more negatively. Whereas differential need is perceived to be a fair reason for differential resource allocation (Kienbaum \& Wilkening, 2009; Schmidt et al., 2016; Sigelman \& Waitzman, 1991), preferential treatment is perceived to be unfair by children at this age (Brown, 2006; Helwig \& Jasiobedzka, 2001).

\section{Method}

\section{Participants}

Participants were $N=139$ children ages $10-11$ years $(M=11.14$ years, $S D=.61$ years). The sample was approximately evenly divided by gender ( $n=63$ male, $n=76$ female). Participant race/ethnicity was obtained by parent report: $36 \%(n=50)$ African-American, $32 \%(n$ $=44)$ European-American, $22 \%(n=30)$ Latino (not in combination with any other racial group), $11 \%(n=15)$ Asian-American. Participants were recruited from eight racially/ethnically diverse elementary schools in the Mid-Atlantic region of the United States. Although no information on individual parental educational attainment or income level was available, across all schools, the percentage of children eligible for the FARMS (Free and Reduced Meals) program ranged from approximately $20 \%$ to approximately $70 \%$. FARMS eligibility is calculated based on a combination of household size and income. Across all schools, the racial composition of the 
school population ranged from approximately $20 \%$ to approximately $40 \%$ African-American students and approximately $10 \%$ to approximately 50\% European-American students (this is relevant because of the race of children depicted in the experimental inequalities, described below). The average parental consent response rate across schools was approximately $70 \%$. Written parental consent and children's verbal assent were obtained for all participants.

\section{Procedure}

Children completed the measures independently, in a quiet space at their school, supervised by trained Research Assistants. All stimuli and measures were presented on a laptop using MediaLab v2012 (Empirisoft Corporation). The entire experimental session took approximately 15 minutes, after which children were guided back to their classrooms. During the assent process, children were told that the research team was interested in "kids' ideas about different social situations". Participants were told that this was not a test, there were no "right or wrong" answers to any of the questions, they could skip questions they did not want to answer or stop participating at any time, and that their responses were confidential and anonymous (i.e., their names would not be linked with their responses, and their responses would not be shown to their "parents, teachers, or other students"). Following their session, each child was individually escorted back to their classroom by a trained Research Assistant. During this walk, the Research Assistant asked the participant what they thought of the study and if they had any questions about the study. Though these conversations were not recorded, participants were generally neutral to positive about their experience.

In order to measure children's self-generated explanations for observed resource inequalities between racial groups (the first aim of the study), participants were shown resource inequalities between institutions serving African-American and European-American children. In 
a within-subjects design, all participants witnessed one context in which African-Americans were disadvantaged and one context in which European-Americans were disadvantaged (see Experimental Inequality). Thus, during the participation session, each measure (Experimental Inequality, Inequality Explanation, Inequality Judgment, Inequality Perpetuation Evaluation) was repeated twice: once in regards to an inequality of medical supplies, and once in regard to an inequality of school supplies, such that participants saw each group disadvantaged once and advantaged once. In this within-subjects design, the questions posed in both contexts were identical. Order of presentation (school first and then hospital versus hospital first and then school) was randomized across participants, and the race of the disadvantaged group was counterbalanced such that participants saw one context in which African-Americans received fewer resources than European-Americans and one context in which European-Americans received fewer resources than African-Americans.

For both contexts (African-American institutions disadvantaged and European-American institutions disadvantaged) children were asked to explain why some institutions had received more resources than others, in an open-ended format (see Inequality Explanation). Children's open-ended responses were coded into categories for quantitative analyses and, in order to address our second aim, we tested for differences in children's explanations based on context (African-Americans disadvantaged versus European-Americans disadvantaged). Further, in order to address our third aim, participants judged the acceptability of the inequality (separately for both contexts, see Inequality Judgment), and evaluated a city leader's decision to perpetuate each inequality by giving more resources to an institution that had received more in the past (also separately for each context, see Inequality Perpetuation Evaluation). 
Thus, in this within-subjects design, the questions posed in both contexts (AfricanAmericans disadvantaged and European-Americans disadvantaged) were identical. To simplify the description of the methods, both contexts are described together below.

\section{Measures}

Experimental inequality. First, participants witnessed four pairings of racial group membership and distribution of supplies to institutions. For each pairing, the following appeared on the laptop screen: two photographs of prototypic buildings (schools or hospitals), two groups of four children's photographs (evenly divided by gender), and the words "These are two schools/hospitals in the same city. There are the same number of kids who go to both schools/hospitals. Here are some of the kids who go to this school/hospital. And here are some of the kids who go to this school/hospital." One group of children depicted was African-American, and one group was European-American. Next, six boxes of supplies (photographs superimposed on images of standard brown cardboard boxes) and the words "In these kids' school/hospital, every classroom/room has six boxes of $[\mathrm{X}]$ to use when the kids are learning/when the kids get sick" appeared under one group of children, and one box of supplies and the words "In these kids' school/hospital, every classroom/room has one box of $[\mathrm{X}]$ to use when the kids are learning/when the kids get sick" appeared under the other group. School supplies were books, calculators, art materials, and notebooks. Hospital supplies were medicine, thermometers, stethoscopes, and bandages. Participants viewed different buildings and groups of children across all trials, but the number of boxes of supplies associated with each racial group varied systematically. The side of the screen on which each racial group appeared was counterbalanced across the four pairings. 
Inequality explanation. Next, all schools or hospitals, groups of children, and supplies re-appeared on the screen together and participants were asked "Why do you think these schools/hospitals have more supplies than these schools/hospitals?" Children responded by typing directly into a free response field.

Open-ended response coding. Children's open-ended explanations were coded for analyses into one of three conceptual categories expected based on previous research (Chafel \& Neitzel, 2005; Flanagan et al., 2014; Killen et al., 2016; Mistry et al., 2012). These included: 1) Preferential Treatment, 2) Differing Financial Resources, and 3) Differing Needs. The responses of children who merely restated the discrepancy as presented (e.g., "Those have less and those have more") and children who stated that they did not know what might have caused the inequality were coded as Circular/Don't Know. Because we had no hypotheses pertaining to children who gave Circular/Don't Know explanations for the inequality, only the responses of children who referenced Preferential Treatment, Differing Financial Resources, and Differing Needs were included in the models presented in the Results section below.

Based on previous research, we also originally included a category for attributions based on merit or effort (Chafel \& Neitzel, 2005; Flanagan et al., 2014; Sigelman, 2013), and a category for attributions based on luck (Sigelman, 2013). However, no children referenced merit/effort or luck as a potential causes for the inequalities, so these categories were eliminated from the coding scheme.

Less than $5 \%$ of participants gave explanations that contained references to two conceptual categories. In these cases, the explanation was coded into a single category according to its most prevalent content. That is, explanations that contained references to two issues (e.g., Preferential Treatment and Differing Needs) were assigned to a single category based on which 
concept comprised the bulk of the participant's response. The content coding of justifications was conducted by two coders blind to the hypotheses of the study. On the basis of $25 \%$ of the data $(n=35$ participants), Cohen's $\kappa=.85$ for inter-rater reliability.

Preferential Treatment was defined as explanations for the inequality based on differential treatment of groups (e.g., "Those hospitals are treated fairly but the others are not because of their race"). Many responses coded as Preferential Treatment included references to the race of students and patients (as in Brown (2006), for example), but this was not a necessary condition for inclusion in this category. For example, "The person in charge is favoring those hospitals" was also coded as Preferential Treatment.

Differing Financial Resources was defined as explanations for the inequality based on the financial or economic resources of the institutions (e.g., "The schools with more supplies are richer than the other schools with less"). In line with other research on attributions for individual economic success or struggles (e.g., Chafel \& Neitzel, 2005; Flanagan et al., 2014; Hussak \& Cimpian, 2015; Mistry et al., 2012), references to neighborhood capital (e.g., "That school is in a richer neighborhood") was also an example of Differing Financial Resources.

Differing Needs was defined as explanations for the inequality based on the assumption that some institutions had a greater need for supplies than others (e.g., "The kids in those hospitals may have worse injuries than the others"). These types of attributions are expected based on research indicating that older children are concerned with recipients' relative needs in resource allocation contexts and demonstrate consideration for recipients' welfare and wellbeing when evaluating unequal distributions of resources that are needed to avoid harm (Rizzo, Elenbaas, Cooley, \& Killen, 2016; Schmidt et al., 2016; Sigelman \& Waitzman, 1991). 
Inequality judgment. Following their inequality explanation, a four-point smiley face rating scale appeared on the screen next to the pictures of the schools or hospitals and supplies, accompanied by the question "How okay or not okay is it that these schools/hospitals have more supplies than these schools/hospitals?" Children indicated their judgment by clicking one of the buttons corresponding to each point on the scale: 1 = "really not okay" to 4 = "really okay".

Inequality perpetuation evaluation. Next two new photographs of schools/hospitals and groups of children appeared on the screen, accompanied by the rating scale. In regards to the institution representing the racial group that had received more resources, children were asked: "What if the person in charge of the city gave more boxes to this school/hospital because they always got more before? How okay or not okay would that be?", and indicated their evaluation using the scale.

\section{Preparation for Data Analyses}

Before testing our hypotheses regarding differences in children's explanations for the inequality based on the race of the disadvantaged group and relations between children's explanations for the inequalities and judgments about the inequalities we conducted a set of preliminary analyses. First, we verified that there were no differences in the proportion of children referencing each explanation category in the school supply (educational) versus medical supply (health care) context. Because there were no significant differences in children's explanations by context (school supplies versus hospital supplies), the two contexts were collapsed in all further analyses. Second, we tested for main and interaction effects of participant race/ethnicity for children's explanations for the inequalities, judgments of the inequalities, and evaluations of actions taken to perpetuate the inequalities. These tests revealed no significant main or interaction effects regardless of whether the responses of children from all four 
racial/ethnic backgrounds were compared or whether the model included only African-American and European-American participants (whose background was depicted in the study stimuli). That is, participants' explanations, judgments, and evaluations did not differ significantly based on participants' own racial/ethnic background.

\section{Results}

\section{Children's Explanations for Resource Inequalities}

As described above, participants were shown two resource inequalities between institutions serving African-American and European-American children in a within-subjects design. First, we assessed the overall frequency with which participants referenced the three different explanations for resource inequality described in the conceptual coding scheme above. Across the two contexts of inequality (school supplies and medical supplies), $42 \%$ of children referenced Differing Financial Resources, approximately one third (34\%) of children mentioned Differing Needs, and approximately one quarter (24\%) of children referenced Preferential Treatment. Finally, $30 \%$ of children made circular statements or were unable to generate an attribution for the disparity (Circular/Don't Know) at least once across the two contexts of inequality (school and medical).

\section{Explanations for Inequalities Differ by the Race of the Disadvantaged Group}

Next, we tested whether children's explanations for the inequalities that they observed differed within-subjects as a function of the race of the disadvantaged group. Confirming our expectations, a McNemar test for Preferential Treatment was significant $(p=.002) ; 23 \%$ of participants $(n=31)$ referenced this explanation when institutions serving African-Americans were disadvantaged whereas $13 \%(n=18)$ referenced it when institutions serving EuropeanAmericans were disadvantaged (see Table 1). References to Differing Financial Resources 


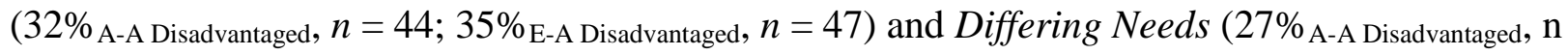
$=36 ; 27 \%_{\text {E-A Disadvantaged, }} \mathrm{n}=36$ ) did not vary significantly by which group was receiving fewer resources, $p=.69$ and $p=1.00$, respectively.

\section{Different Explanations Predict Judgments of the Wrongfulness of Inequalities}

Initial analyses revealed no significant differences in children's judgments of the wrongfulness of the inequalities by the race of the disadvantaged group. Thus, in order to test our hypotheses regarding differences in children's judgments based on their explanations for the cause of the inequalities that they observed, we conducted two separate ANOVAs, one for the context in which African-American institutions were disadvantaged, and one for the context in which European-American institutions were disadvantaged. For both ANOVAs, we tested the hypothesis that children who explained the resource inequality in terms of Preferential Treatment or Differing Financial Resources would judge it more negatively than children who attributed the inequality to other factors. Thus, for both ANOVAs, the independent variable was Explanation (3: Preferential Treatment, Differing Financial Resources, Differing Needs), and the dependent variable was children's judgment of the wrongfulness of the inequality $(1=$ "really not okay" to 4 = "really okay"). For these ANOVAs, and for all ANOVAs reported in this paper, follow-up tests for significant effects were conducted with Bonferroni correction for multiple comparisons. As noted above, we did not include participant race in these models. However, the inclusion of participant race results in no further significant main or interaction effects, and does not alter the pattern of significance presented below.

For the context where African-American institutions were disadvantaged, the ANOVA revealed a main effect of Explanation, $F(2,108)=13.29, p<.001, \eta_{\mathrm{p}}{ }^{2}=.20$ (see Figure 1). Follow-up tests supported our predictions, revealing that children who referenced Preferential 
Treatment $(M=1.26, S D=.44)$ and children who referenced Differing Financial Resources $(M$ $=1.41, S D=.62)$ judged the inequality more negatively than children who referenced Differing Needs $(M=2.03, S D=.84)$, both $p s<.001$. The judgments of children who referenced Preferential Treatment and children who referenced Differing Financial Resources did not differ significantly from each other $(p=1.00)$.

When European-American institutions were disadvantaged, the ANOVA also revealed a main effect of Explanation, $F(2,98)=6.85, p=.002, \eta_{\mathrm{p}}{ }^{2}=.12$ (see Figure 2). Follow-up tests indicated that children who referenced Preferential Treatment $(M=1.22, S D=.55)$ and children who referenced Differing Financial Resources $(M=1.36, S D=.53)$ judged the inequality more negatively than children who referenced Differing Needs $(M=1.83, S D=.87)$, all $p s=.007$, further supporting our hypotheses. The judgments of children who referenced Preferential Treatment and children who referenced Differing Financial Resources did not differ significantly from each other $(p=1.00)$.

Thus, both when African-American institutions and when European-American institutions were disadvantaged, children who explained the inequalities in terms of biased or preferential treatment of the groups (Preferential Treatment) or differing financial resources of the institutions (Differing Financial Resources) judged them to be more wrong than children who assumed that some institutions had a greater need for supplies than others (Differing Needs).

\section{Different Explanations Predict Evaluations of Actions Taken to Perpetuate Inequalities}

Initial analyses revealed no significant differences in children's judgments of actions taken to perpetuate the inequalities by the race of the disadvantaged group. Thus, in order to test our hypotheses regarding differences in children's judgments of these actions based on their explanations for the cause of the inequalities, we conducted two separate ANOVAs, one for the 
context in which African-American institutions were disadvantaged, and one for the context in which European-American institutions were disadvantaged. For both ANOVAs, we tested the hypothesis that children who explained the resource inequality in terms of Preferential Treatment or Differing Financial Resources would evaluate actions taken to perpetuate inequality more negatively than children who attributed the inequality to other factors. Thus, for both ANOVAs, the independent variable was Explanation (3: Preferential Treatment, Differing Financial Resources, Differing Needs), and the dependent variable was children's evaluation of the wrongfulness of actions taken to perpetuate the inequality $(1=$ "really not okay" to $4=$ "really okay"). As above, we did not include participant race in these models; the inclusion of participant race results in no further significant main or interaction effects, and does not alter the pattern of significance presented below.

For the context where African-American institutions were disadvantaged, the ANOVA revealed a main effect of Explanation, $F(2,108)=11.26, p<.001, \eta_{\mathrm{p}}{ }^{2}=.17$ (see Figure 3). Supporting our predictions, children who referenced Preferential Treatment $(M=1.23, S D=.43)$ and children who referenced Differing Financial Resources $(M=1.48, S D=.59)$ evaluated actions taken to perpetuate the inequality more negatively than children who referenced Differing Needs $(M=1.97, S D=.88), p<.001$ and $p=.004$, respectively. The evaluations of children who referenced Preferential Treatment and children who referenced Differing Financial Resources did not differ significantly from each other $(p=.33)$. These findings parallel those found in the model predicting children's judgments about the wrongfulness of the inequality (above). That is, when African-American institutions were disadvantaged, children who explained the inequality in terms Preferential Treatment or Differing Financial Resources evaluated actions taken to 
perpetuate the inequality more negatively than children who assumed that some institutions had a greater need for supplies than others (Differing Needs).

When European-American institutions were disadvantaged, the ANOVA also revealed a main effect of Explanation, $F(2,98)=4.09, p=.02, \eta_{\mathrm{p}}{ }^{2}=.08$ (see Figure 4). Follow-up tests provided partial support for our hypotheses, revealing that children who referenced Preferential Treatment $(M=1.28, S D=.46)$ evaluated actions taken to perpetuate the inequality significantly more negatively than children who referenced Differing Needs $(M=1.81, S D=.79), p=.02$. However, while the evaluations of children who referenced Differing Financial Resources ( $M=$ $1.53, S D=.62$ ) did not differ significantly from the evaluations of children who referenced Preferential Treatment $(p=.51)$, they also did not differ significantly from the evaluations of children who referenced Differing Needs $(p=.20)$. Thus, when European-American institutions were disadvantaged, children who explained the inequality in terms of Preferential Treatment, but not children who explained it in terms of Differing Financial Resources, evaluated actions taken to perpetuate the inequality more negatively than children who attributed it to Differing Needs.

\section{Discussion}

The novel findings from this study revealed how children reason about inequalities of societal resources between racial groups, and how recognition of the social factors underlying resource inequalities contribute to rejection of these disparities. Unlike previous research on children's appeals to merit when explaining wealth and poverty, children did not explain racial disparities in access to educational and health care resources in terms of effort or intelligence. Instead, 10-11 year-olds most often referenced institutions' differing financial resources, showing awareness that economic disparities often underlie group-based differences in access to 
societal resources. Further, children were more likely to attribute the inequality to biased or preferential treatment when they observed African-Americans receiving fewer resources, demonstrating awareness that racial minority groups are more likely to be the targets of discrimination in the form of differential resource allocation. Finally, children who explained the resource inequalities that they observed in terms of preferential treatment consistently judged the inequalities and discriminatory actions aimed at perpetuating them to be more wrong than children who reasoned about other factors, highlighting a direct link between understanding some of the societal causes underlying groups' differential access to resources and rejection of social inequalities.

Considerable research has focused on the negative aspects of group membership on children's treatment of others (e.g., in-group biases, prejudice). However, one important prediction of the social reasoning developmental (SRD) model is that, in some cases, knowledge about intergroup relations can support children's decisions to challenge unfair group practices, including differential distribution of important resources between groups (Killen \& Rutland, 2011). These results provide support for our prediction, because children who perceived the resource inequality to be discriminatory (reflecting preferential treatment) were more likely to judge it as wrong. Thus, children who recognized that intergroup relations had been unjust in the past were able to use that knowledge to reject attempts to perpetuate unfair patterns.

Unlike individual differences in economic status, race-related differences in access to societal resources are group-level concerns, bringing group-level factors like associations of race and wealth to the forefront. In this study, we presented participants with several concrete examples of unequal allocation of educational and health care resources based on race, and measured their self-generated explanations for the inequality. Importantly, whereas previous 
research has shown that children often justify individual economic success or failure with reference to effort/merit or personal deficits, no participants in this study referenced these factors. Instead, they most commonly explained observed inequalities in terms of financial capital. That is, $42 \%$ of $10-11$ year-old participants cited differential access to money, funding, or other economic factors as an explanation for at least one of the resource inequalities that they observed. This highlights an important difference between children's reasoning about economic inequality on an individual level versus reasoning about group-based resource inequality. Our results reveal that children begin to explain group-based societal resource disparities in terms of economic inequality by at least $10-11$ years of age.

Notably, children's reasoning also revealed their emerging understanding of the role of race in access to educational and health care resources. Specifically, 10-11 year-olds were more likely to explain an observed inequality in terms of preferential treatment when they saw institutions serving African-American children receiving fewer supplies (23\%) than when they saw institutions serving European-American children receiving fewer supplies (13\%). These findings extend the growing body of literature indicating that as early as middle childhood (e.g., 10-11 years of age), children increasingly recognize that certain racial groups are more likely to be the targets of discrimination than other groups (Bigler et al., 2008; Brown et al., 2007; J. M. Hughes, 2011). Little work has examined the intersection of resource allocation and perceptions of discrimination, yet these new findings indicate that this is an important context in which children are able to detect and explicitly reason about preferential treatment. It is likely that the concrete, visual examples of differential resource allocation helped many children to recognize bias by 10-11 years of age. 
Critically, children who attributed inequalities of societal resources to preferential treatment of one racial group over another judged them, and actions taken to perpetuate them, as more wrong than their peers who attributed observed disparities to groups' differing need for resources. These findings emerged regardless of whether children saw African-American or European-American institutions disadvantaged, and provide direct evidence for the relation between children's reasoning about social inequality and their subsequent responses to it. That is, although participants were more likely to attribute the inequality to preferential treatment when they saw institutions serving African-Americans receiving fewer supplies (as discussed above), children who interpreted the inequality as a form of preferential treatment made more negative judgments about it no matter which group was targeted for restricted access to resources.

Previous research indicates that, by late childhood, children endorse their own and others' rights to quality education and medical care (Peterson-Badali et al., 2004). While this previous work has emphasized children's concern for others' welfare in their judgments about the wrongfulness of unequal access to resources like these, this study provides new evidence that children who recognized unequal access as a form of preferential treatment made the most consistently negative moral judgments about social inequalities. Interestingly many children explicitly referenced racial bias the cause; as one child put it, "They're judging people by the color of their skin and that's not right. Who is even running this city? That mayor should get fired".

Perceptions of inequality established in childhood have the potential to continue into adulthood (Abrams \& Killen, 2014; Brown \& Bigler, 2005). Thus, future efforts to increase children's awareness of social inequality or expand opportunities for disadvantaged groups in childhood may be able to draw on these findings indicating that, by 10-11 years of age, children 
who detect group biases as underlying broad resource disparities are especially likely to reject inequalities, whereas children who are unaware of these social factors are less critical of the status quo.

Interestingly, approximately one third of children assumed that some institutions had a greater need for supplies than others, resulting in a resource inequality. Related research on children's own resource allocation decisions indicates that, with age, children increasingly consider the relative needs of recipients when allocating small items like toys and candy (Kienbaum \& Wilkening, 2009; Rizzo et al., 2016; Schmidt et al., 2016; Sigelman \& Waitzman, 1991), indicating that differential need is perceived to be a fair and valid reason for differential resource allocation by middle childhood. These related findings can be used to understand why children who reasoned along these lines were more accepting of the inequality and actions taken to perpetuate it. While several studies show that children reject unequal allocation of resources needed to avoid harm on the grounds that all groups need access to these resources (e.g., Helwig \& Jasiobedzka, 2001; Killen et al., 2002), our findings show that children sometimes employ the reverse rationale. That is, when children believe that unequal distribution of societal resources is necessary in order to accommodate groups' differing needs, they are more likely to support continued unequal allocation because they assume that such behavior helps children in need.

Finally, we included a racially/ethnically diverse participant sample in order to determine whether or not children's own racial/ethnic background would impact their perceptions of social inequality (as presented). This possibility, however, was not borne out in the current study. Neither explanations, nor judgments, nor evaluations differed significantly by participant race/ethnicity. In this context, what may be more relevant than children's membership in a racial/ethnic group alone are personal experiences with differential treatment as a result of one's 
group membership. It is notable that, with age, many adolescents, and particularly adolescents of African-American and Latino background, report increasing personal experiences with discrimination from teachers, peers, and strangers, with reports ranging from wrongful discipline in school to being hassled by store clerks to teasing and online harassment (Douglass, Mirpuri, English, \& Yip, 2016; Fisher, Wallace, \& Fenton, 2000; Rivas-Drake, Hughes, \& Way, 2009; Umaña-Taylor, Tynes, Toomey, Williams, \& Mitchell, 2015). Thus, it may be that, later in development (i.e., later in adolescence), increasing personal experiences with others' biases would be associated with greater recognition of discriminatory resource allocation for racial/ethnic minority adolescents. Although differences by participant race/ethnicity did not emerge for this sample of 10-11 year-olds, the race of the target group was clearly a salient variable in children's perceptions of social resource inequality, particularly in regards to detecting and negatively evaluating preferential treatment, as described above.

\section{Limitations, Future Directions, and Conclusions}

This study sampled 10-11 year-olds attending racially/ethnically and socioeconomically diverse schools. An important next step is to examine potential differences in children's perceptions of race-based social inequalities based on their own access to these important resources. Recent research indicates that children and adolescents from lower-SES backgrounds may have a more detailed understanding of the implications of reduced access to resources than their higher-SES peers (Chafel \& Neitzel, 2005; Mistry et al., 2012), and that adolescents from families with higher levels of parental education are more likely to reason about economic inequality in terms of structural factors (Flanagan et al., 2014). Future research could investigate the joint and separate roles of target group and participant race and SES on developing perceptions of educational and health care inequalities. 
Additionally, in the current study, we presented children with clear and unambiguous examples of differential resource allocation between African-American and European-American children, and found no differences in explanations for the inequality based on participant race. An alternative approach for future studies could entail investigating children's expectations for how resources would be distributed between institutions serving children of different racial backgrounds (rather than their explanations for an inequality after-the-fact). In this case, participants who personally experience restricted access to resources as a result of their experiences as members of a disadvantaged group may be more likely to perceive or anticipate the potential for inequality between institutions serving children of different racial backgrounds. This possibility remains open for future investigation.

As biases are often fixed by adulthood, research on children's reasoning about groupbased inequality provides a window into areas for intervention in childhood. We found that children in this study varied considerably in their explanations for the inequalities that they observed, and that different explanations predicted different judgments of the wrongfulness of resource inequality and actions taken to perpetuate it. Additionally, although the majority of participants were able to generate a potential explanation for both inequalities, $30 \%$ merely acknowledged the disparity with no further elaboration (e.g., "It just is") or stated that they did not know why the inequality might exist at least once across the two contexts.

This indicates that future research might benefit from asking targeted follow-up questions regarding children's perceptions of different factors contributing to inequality. For instance, future studies could use an individual interview method (rather than asking participants to answer independently), in order to further probe children's initial responses. As one example, children who answered "The schools with more supplies are richer than the other schools with 
less" (an example of Differing Financial Resources) could be asked the follow-up question "Why are these schools richer?" in order to reveal additional complexities in children's reasoning about inequality. Alternatively, future studies might present a series of questions following children's initial response, in order to gauge children's endorsement of different potential causes including preferential treatment, differing financial resources, and differing needs (as in the current study), as well as alternative explanations including merit, effort, and luck, which have been noted in related research in this area. This approach has the potential benefit of providing data for relative comparisons. For example, to what extent do children endorse preferential treatment versus differing financial resources as competing or converging possible causes of inequality?

Additionally, the diversity of children's reasoning about group-based inequality and the results indicating that different perceptions for the causes of inequality predict different judgments about the wrongfulness of race-based disparities point to fifth grade (10-11 years) as an ideal time for targeted instruction on the causes of social inequality. At this age, children are beginning to identify discrimination (e.g., Brown, 2006) and consider others' rights to societal resources (e.g., Peterson-Badali et al., 2004). Thus, fifth graders may be an ideal population for policy and education programs aimed at helping children challenge the status quo.

This study highlighted 10-11 year-olds' emerging awareness that economic disparities and preferential treatment (discrimination) often underlie race-based differences in access to societal resources. Further, relations between children's reasoning, judgments, and evaluations revealed direct links between understanding some of the societal causes underlying groups' differential access to resources and rejection of social inequalities. Extending previous research emphasizing children's reasoning about fairness and other's welfare in resource allocation 
contexts (Killen \& Smetana, 2015), findings from the current study point to a new area for research on children's social and moral development: reasoning about and responses to social inequality. 


\section{References}

Abrams, D., \& Killen, M. (2014). Social exclusion of children: Developmental origins of prejudice. Journal of Social Issues, 70, 1-11. doi:10.1111/josi.12043

Abrams, D., \& Rutland, A. (2008). The development of subjective group dynamics. In S. R. Levy \& M. Killen (Eds.), Intergroup attitudes and relations in childhood through adulthood. (pp. 47-65). New York, NY: Oxford University Press.

Arsenio, W. F., Preziosi, S., Silberstein, E., \& Hamburger, B. (2013). Adolescents' perceptions of institutional fairness: Relations with moral reasoning, emotions, and behavior. In T. Malti (Ed.), Adolescent emotions: Development, morality, and adaptation. (pp. 95-110). San Francisco, CA: Jossey-Bass.

Bigler, R. S., Arthur, A. E., Hughes, J. M., \& Patterson, M. M. (2008). The politics of race and gender: Children's perceptions of discrimination and the U.S. presidency. Analyses of Social Issues and Public Policy, 8, 83-112. doi:10.1111/j.1530-2415.2008.00161.x

Bigler, R. S., Averhart, C. J., \& Liben, L. S. (2003). Race and the workforce: Occupational status, aspirations, and stereotyping among African American children. Developmental Psychology, 39, 572-580. doi:10.1037/0012-1649.39.3.572

Brown, C. S. (2006). Bias at school: Perceptions of racial/ethnic discrimination among Latino and European American children. Cognitive Development, 21, 401-419. doi:10.1016/j.cogdev.2006.06.006

Brown, C. S., Alabi, B. O., Huynh, V. W., \& Masten, C. L. (2011). Ethnicity and gender in late childhood and early adolescence: Group identity and awareness of bias. Developmental Psychology, 47, 463-471. doi:10.1037/a0021819

Brown, C. S., \& Bigler, R. S. (2005). Children's perceptions of discrimination: A developmental 
model. Child Development, 76, 533-553. doi:10.1111/j.1467-8624.2005.00862.x

Brown, C. S., Mistry, R. S., \& Bigler, R. S. (2007). Hurricane Katrina: African American children's perceptions of race, class, and government involvement amid a national crisis. Analyses of Social Issues and Public Policy, 7, 191-208. doi:10.1111/j.15302415.2007.00139.x

Bucchianeri, M. M., Eisenberg, M. E., \& Neumark-Sztainer, D. (2013). Weightism, racism, classism, and sexism: Shared forms of harassment in adolescents. Journal of Adolescent Health, 53, 47-53. doi:10.1016/j.jadohealth.2013.01.006

Chafel, J. A., \& Neitzel, C. (2005). Young children's ideas about the nature, causes, justification, and alleviation of poverty. Early Childhood Research Quarterly, 20, 433-450. doi:10.1016/j.ecresq.2005.10.004

Douglass, S., Mirpuri, S., English, D., \& Yip, T. (2016). “They were just making jokes”: Ethnic/racial teasing and discrimination among adolescents. Cultural Diversity and Ethnic Minority Psychology, 22, 69-82. doi:10.1037/cdp0000041

Duncan, G. J., \& Murnane, R. J. (Eds.). (2011). Whither opportunity? Rising inequality, schools, and children's life chances. New York, NY: Russell Sage Foundation.

Elenbaas, L., \& Killen, M. (2016a). Age-related changes in children's associations of economic resources and race. Frontiers in Psychology, 7, 884. doi:10.3389/fpsyg.2016.00884

Elenbaas, L., \& Killen, M. (2016b). Children rectify inequalities for disadvantaged groups. Developmental Psychology, 8, 1318-1329. doi:10.1037/dev0000154

Fisher, C. B., Wallace, S. A., \& Fenton, R. E. (2000). Discrimination distress during adolescence. Journal of Youth and Adolescence, 26, 679-695. doi:10.1023/A:1026455906512 
Flanagan, C. A., Kim, T., Pykett, A., Finlay, A., Gallay, E. E., \& Pancer, M. (2014).

Adolescents' theories about economic inequality: Why are some people poor while others are rich? Developmental Psychology, 50, 2512-2525. doi:10.1037/a0037934

Goodman, E., Amick, B. C., Rezendes, M. O., Levine, S., Kagan, J., Rogers, W. H., \& Tarlov, A. R. (2000). Adolescents' understanding of social class: A comparison of white upper middle class and working class youth. Journal of Adolescent Health, 27, 80-83. doi:10.1016/S1054-139X(99)00116-0

Helwig, C. C., \& Jasiobedzka, U. (2001). The relation between law and morality: Children's reasoning about socially beneficial and unjust laws. Child Development, 72, 1382-93. doi:10.1111/1467-8624.00354

Hitti, A., \& Killen, M. (2015). Expectations about ethnic peer group inclusivity: The role of shared interests, group norms, and stereotypes. Child Development, 86, 1522-1537. doi:10.11.11/cdev.12393

Horwitz, S. R., Shutts, K., \& Olson, K. R. (2014). Social class differences produce social group preferences. Developmental Science, 17, 991-1002. doi:10.1111/desc.12181

Hughes, D. (2003). Correlates of African American and Latino parents' messages to children about ethnicity and race: A comparative study of racial socialization. American Journal of Community Psychology, 31, 15-33. doi:10.1023/a:1023066418688

Hughes, J. M. (2011). Influence of discrimination awareness on the occupational interests of African American children. Journal of Applied Developmental Psychology, 32, 369-378. doi:10.1016/j.appdev.2011.08.003

Hughes, J. M., \& Bigler, R. S. (2011). Predictors of African American and European American adolescents' endorsement of race-conscious social policies. Developmental Psychology, 47, 
479-492. doi:10.1037/a0021309

Hussak, L. J., \& Cimpian, A. (2015). An early-emerging explanatory heuristic promotes support for the status quo. Journal of Personality and Social Psychology, 109, 739-752. doi:10.1037/pspa0000033

Jost, J. T., \& Banaji, M. R. (1994). The role of stereotyping in system-justification and the production of false consciousness. British Journal of Social Psychology, 33, 1-27. doi:10.1111/j.2044-8309.1994.tb01008.x

Jost, J. T., Banaji, M. R., \& Nosek, B. A. (2004). A decade of system justification theory: Accumulated evidence of conscious and unconscious bolstering of the status quo. Political Psychology, 25, 881-919.

Kienbaum, J., \& Wilkening, F. (2009). Children's and adolescents' intuitive judgements about distributive justice: Integrating need, effort, and luck. European Journal of Developmental Psychology, 6, 481-498. doi:10.1080/17405620701497299

Killen, M., Elenbaas, L., Rizzo, M. T., \& Rutland, A. (2016). The role of group processes in social exclusion and resource allocation decisions. In A. Rutland, D. Nesdale, \& C. Spears Brown (Eds.), Handbook of group processes in children and adolescents. New York, NY: Wiley-Blackwell.

Killen, M., Elenbaas, L., \& Rutland, A. (2015). Balancing the fair treatment of others while preserving group identity and autonomy. Human Development, 58, 253-272. doi:10.1159/000444151

Killen, M., Lee-Kim, J., McGlothlin, H., \& Stangor, C. (2002). How children and adolescents evaluate gender and racial exclusion. Monographs of the Society for Research in Child Development, 67, 1-129. doi:10.1111/1540-5834.00218 
Killen, M., \& Rutland, A. (2011). Children and social exclusion: Morality, prejudice, and group identity. Wiley-Blackwell. doi:10.1002/9781444396317

Killen, M., \& Smetana, J. G. (2015). Origins and development of morality. In M. E. Lamb (Ed.), Handbook of child psychology and developmental science, Vol. 3 (7th ed., pp. 701-749). New York, NY: Wiley-Blackwell.

Levy, S. R., West, T. L., \& Ramirez, L. (2005). Lay theories and intergroup relations: A socialdevelopmental perspective. European Review of Social Psychology, 16, 189-220. doi:10.1080/10463280500397234

McGillicuddy-De Lisi, A. V, Daly, M., \& Neal, A. (2006). Children's distributive justice judgments: Aversive racism in Euro-American children? Child Development, 77, 10631080. doi:10.1111/j.1467-8624.2006.00919.x

McKown, C. (2004). Age and ethnic variation in children's thinking about the nature of racism. Journal of Applied Developmental Psychology, 25, 597-617. doi:10.1016/j.appdev.2004.08.001

McKown, C., \& Strambler, M. J. (2009). Developmental antecedents and social and academic consequences of stereotype-consciousness in middle childhood. Child Development, 80 , 1643-1659. doi:10.1111/j.1467-8624.2009.01359.x

McKown, C., \& Weinstein, R. S. (2003). The development and consequences of stereotype consciousness in middle childhood. Child Development, 74, 498-515. doi:10.1111/14678624.7402012

Mistry, R. S., Brown, C. S., Chow, K. A., \& Collins, G. S. (2012). Increasing the complexity of young adolescents' beliefs about poverty and inequality: Results of an 8th grade social studies curriculum intervention. Journal of Youth and Adolescence, 41, 704-716. 
doi:10.1007/s10964-011-9699-6

Mistry, R. S., Brown, C. S., White, E. S., Chow, K. A., \& Gillen-O’Neel, C. (2015). Elementary school children's reasoning about social class: A mixed-methods study. Child Development, 86, 1653-1671. doi:10.1111/cdev.12407

Mulvey, K. L., Hitti, A., Rutland, A., Abrams, D., \& Killen, M. (2014). When do children dislike ingroup members? Resource allocation from individual and group perspectives. Journal of Social Issues, 70, 29-46. doi:10.1111/josi.12045

Mulvey, K. L., \& Killen, M. (2015). Challenging gender stereotypes: Resistance and exclusion. Child Development, 86, 681-694. doi:10.1111/cdev.12317

Nesdale, D. (2004). Social identity processes and children's ethnic prejudice. In M. Bennett \& F. Sani (Eds.), The development of the social self. (pp. 219-245). New York, NY: Psychology Press. doi:10.4324/9780203391099_chapter_8

Newheiser, A.-K., \& Olson, K. R. (2012). White and Black American children's implicit intergroup bias. Journal of Experimental Social Psychology, 48, 264-270. doi:10.1016/j.jesp.2011.08.011

Olson, K. R., Dweck, C. S., Spelke, E. S., \& Banaji, M. R. (2011). Children's responses to group-based inequalities: Perpetuation and rectification. Social Cognition, 29, 270-287. doi:10.1521/soco.2011.29.3.270

Pahlke, E., Bigler, R. S., \& Suizzo, M.-A. (2012). Relations between colorblind socialization and children's racial bias: Evidence from European American mothers and their preschool children. Child Development, 83, 1164-1179. doi:10.1111/j.1467-8624.2012.01770.x

Peterson-Badali, M., Morine, S. L., Ruck, M. D., \& Slonim, N. (2004). Predictors of maternal and early adolescent attitudes toward children's nurturance and self-determination rights. 
Journal of Early Adolescence, 24, 159-179. doi:10.1177/0272431603262667

Rivas-Drake, D., Hughes, D., \& Way, N. (2009). A preliminary analysis of associations among ethnic racial socialization, ethnic discrimination, and ethnic identity among urban sixth graders. Journal of Research on Adolescence, 19, 558-584. doi:10.1111/j.15327795.2009.00607.x

Rizzo, M. T., Elenbaas, L., Cooley, S., \& Killen, M. (2016). Children's recognition of fairness and others' welfare in a resource allocation task: Age related changes. Developmental Psychology, 8, 1307-1317. doi:10.1037/dev0000134

Rutland, A., Killen, M., \& Abrams, D. (2010). A new social-cognitive developmental perspective on prejudice: The interplay between morality and group identity. Perspectives on Psychological Science, 5, 279-291. doi:10.1177/1745691610369468

Saegert, S. C., Adler, N. E., Bullock, H. E., Cauce, A. M., Liu, W. M., \& Wyche, K. F. (2007). Report of the APA Task Force on Socioeconomic Status. Washington, D.C. Retrieved from https://www.apa.org/pi/ses/resources/publications/task-force-2006.pdf

Schmidt, M. F. H., Svetlova, M., Johe, J., \& Tomasello, M. (2016). Children's developing understanding of legitimate reasons for allocating resources unequally. Cognitive Development, 37, 42-52. doi:10.1016/j.cogdev.2015.11.001

Shutts, K., Brey, E. L., Dornbusch, L. A., Slywotzky, N., \& Olson, K. R. (2016). Children use wealth cues to evaluate others. PLOS ONE, 11, e0149360. doi:10.1371/journal.pone.0149360

Sigelman, C. K. (2012). Rich man, poor man: Developmental differences in attributions and perceptions. Journal of Experimental Child Psychology, 113, 415-429. doi:10.1016/j.jecp.2012.06.011 
Sigelman, C. K. (2013). Age differences in perceptions of rich and poor people: Is it skill or luck? Social Development, 22, 1-18. doi:10.1111/sode.12000

Sigelman, C. K., \& Waitzman, K. A. (1991). The development of distributive justice orientations: Contextual influences on children's resource allocations. Child Development, 62, 1367-1378. doi:10.2307/1130812

Smetana, J. G., Jambon, M., \& Ball, C. (2014). The social domain approach to children's moral and social judgments. In M. Killen \& J. G. Smetana (Eds.), Handbook of moral development (2nd ed., pp. 23-45). New York, NY: Psychology Press.

Turiel, E. (2006). The development of morality. In N. Eisenberg, W. Damon, \& R. M. Lerner (Eds.), Handbook of child psychology: Vol. 3. Social, emotional, and personality development (6th ed., pp. 863-932). Hoboken, NJ: John Wiley \& Sons Inc.

Umaña-Taylor, A. J., Tynes, B. M., Toomey, R. B., Williams, D. R., \& Mitchell, K. J. (2015). Latino adolescents' perceived discrimination in online and offline settings: An examination of cultural risk and protective factors. Developmental Psychology, 51, 87-100. doi:10.1037/a0038432

Verkuyten, M. (2007). Ethnic in-group favoritism among minority and majority groups: Testing the self-esteem hypothesis among preadolescents. Journal of Applied Social Psychology, 37, 486-500. doi:10.1111/j.1559-1816.2007.00170.x

Woods, T. A., Kurtz-Costes, B., \& Rowley, S. J. (2005). The development of stereotypes about the rich and poor: Age, race, and family income differences in beliefs. Journal of Youth and Adolescence, 34, 437-445. doi:10.1007/s10964-005-7261-0 
Table 1.

Children's Explanations for Resource Inequality Differ by the Race of the Disadvantaged Group

\begin{tabular}{|c|c|c|}
\hline & $\begin{array}{c}\text { African-American Institutions } \\
\text { Disadvantaged }\end{array}$ & $\begin{array}{c}\text { European-American Institutions } \\
\text { Disadvantaged }\end{array}$ \\
\hline $\begin{array}{l}\text { Preferential } \\
\text { Treatment }\end{array}$ & $0.23^{*}$ & $0.13^{*}$ \\
\hline $\begin{array}{l}\text { Differing Financial } \\
\text { Resources }\end{array}$ & 0.32 & 0.35 \\
\hline Differing Needs & 0.27 & 0.27 \\
\hline
\end{tabular}

Note. Numbers reflect observed proportions. * indicates a difference in the proportion of participants referencing the conceptual category at $p<.05$. 


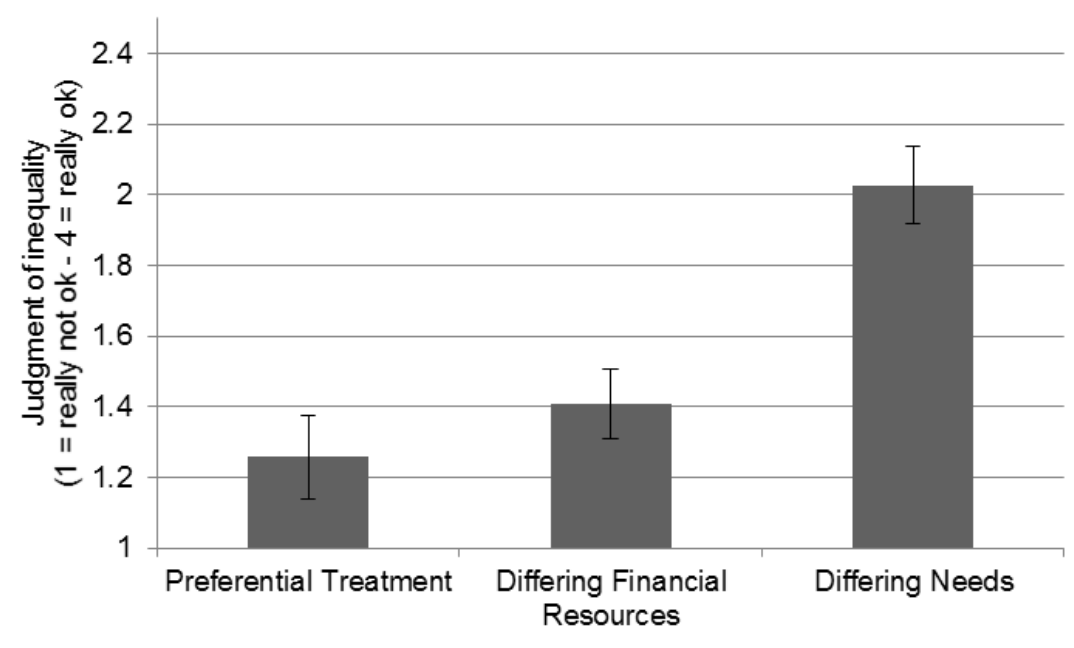

Figure 1. Different explanations predict different judgments of the wrongfulness of resource inequality: African-American institutions disadvantaged. 


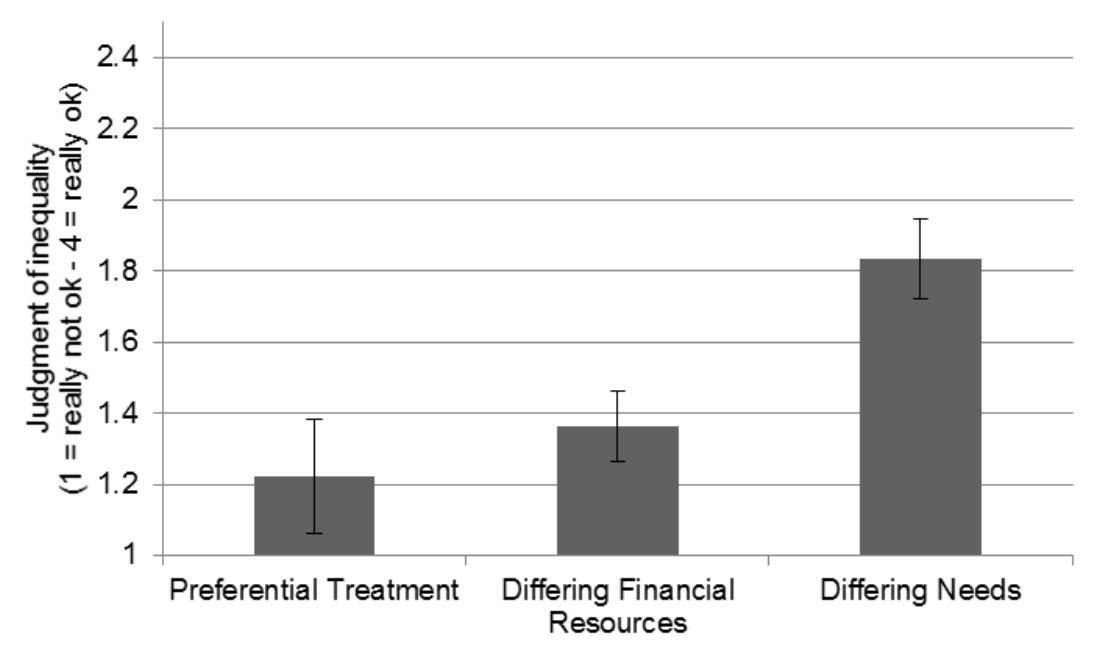

Figure 2. Different explanations predict different judgments of the wrongfulness of resource inequality: European-American institutions disadvantaged. 


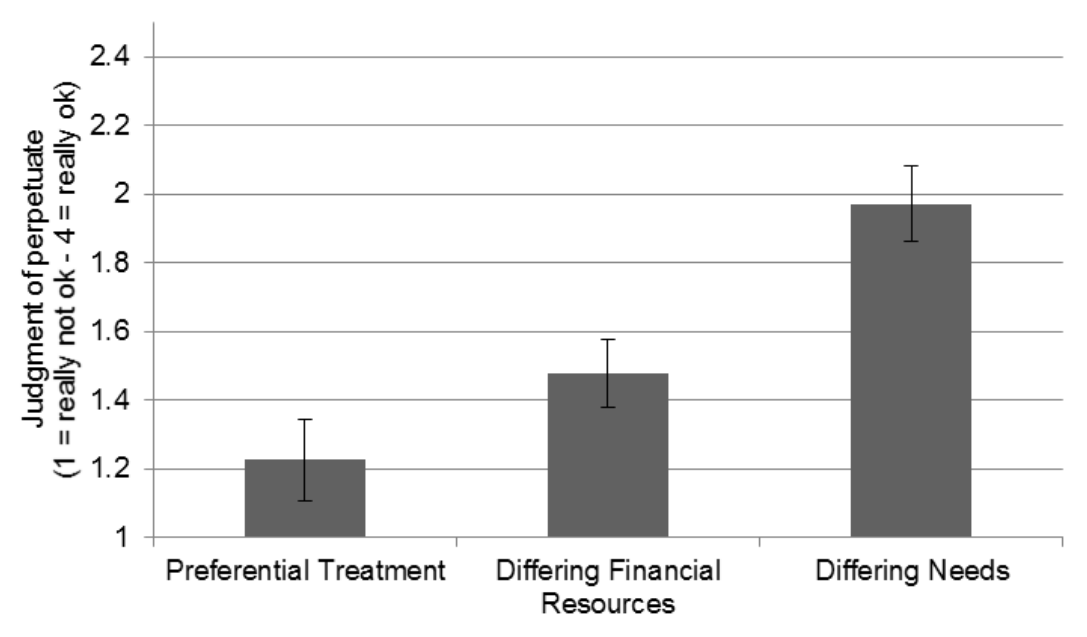

Figure 3. Different explanations predict different evaluations of actions taken to perpetuate resource inequality: African-American institutions disadvantaged. 


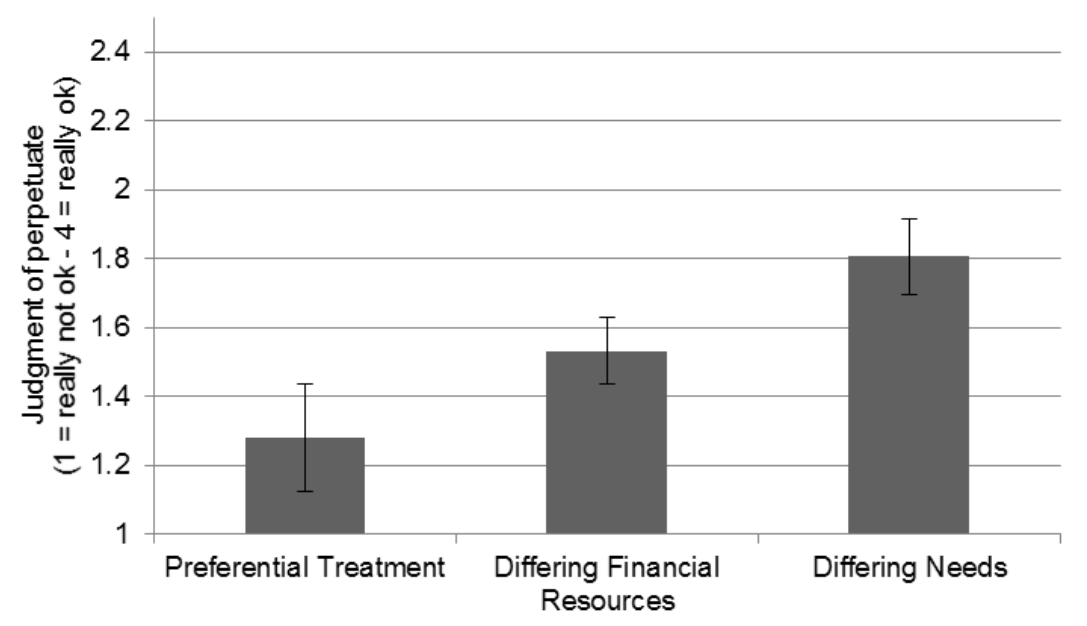

Figure 4. Different explanations predict different evaluations of actions taken to perpetuate resource inequality: European-American institutions disadvantaged. 
Children's Perceptions of Social Resource Inequality

\author{
Laura Elenbaas \& Melanie Killen \\ University of Maryland
}

submitted to the Journal of Applied Developmental Psychology October 15, 2015

revised and resubmitted June 21, 2016

revised and resubmitted October 3, 2016

Correspondence concerning this article should be addressed to Laura Elenbaas, University of Maryland, Department of Human Development and Quantitative Methodology, 3942 Campus Drive, Suite 3304, College Park, MD, 20742-1131.

Contact: elenbaas@umd.edu; 301-405-8769 (phone); 301-405-2891 (fax).

Acknowledgements

This material is based upon work supported by the National Science Foundation Graduate Research Fellowship Program under Grant No. DGE 1322106. The first author was also supported as a trainee on a National Institute of Child Health and Human Development (NIH) Training Program (\#T32HD007542) during the execution of this study. Appreciation is extended to the Society for the Psychological Study of Social Issues for a Clara Mayo Grant award. We thank Michael T. Rizzo, Shelby Cooley, and Jeeyoung Noh for invaluable feedback on the project. We acknowledge the helpful undergraduate research assistance from Sharon Chan, Emily DeMent, Tara Moores, and Taryn Quaytman. We thank the students, parents, and teachers who participated in this study. 